\title{
Flare or foe? - Mycobacterium marinum infection mimicking rheumatoid arthritis tenosynovitis: case report and literature review
}

\author{
Nils Schubert ${ }^{1}$, Tillmann Schill ${ }^{2}$, Marlene Plüß ${ }^{1}$ and Peter Korsten ${ }^{1 *}$ (D)
}

\begin{abstract}
Background: Rheumatoid arthritis is the most common type of inflammatory arthritis affecting about 1\% of the population. With the advent of disease-modifying anti-rheumatic drugs the disease can be well controlled in many cases. Patients, however, are prone to developing infectious complications. In rare cases, these can mimic a flare of the underlying itself.

Case presentation: We report the case of a 45-year-old female patient with a history of seronegative rheumatoid arthritis (RA) who presented with swelling and tenderness of the third metacarpophalangeal joint of the right hand. A flare of her RA was suspected based on clinical and ultrasound findings which showed a tenosynovitis with intense power doppler activity. Her steroid dose was increased but the clinical response to glucocorticoid therapy was very limited. Subsequently, she developed skin manifestations of 'swimmer's granuloma' over the next 2 weeks after first presentation. Finally, a diagnosis of a Mycobacterium marinum infection was established with the help of tissue biopsy and culture, and the patient received appropriate antibiotic treatment with the desired effect.

Conclusions: This case highlights the difficulty of distinction between infection and inflammation in patients with joint swelling and pain, especially in the age of disease-modifying drugs (DMARDs) and the concomitant risk of atypical infections. A review of the literature identified eight additional published cases, which suggests that Mycobacterium marinum infection is a rare but recognized complication of DMARD therapy. It can mimic a flare of the underlying arthritis potentially leading to diagnostic delays, and requires differential diagnostic methods to identify the pathogen and pave the way for appropriate treatment.
\end{abstract}

Keywords: Rheumatoid arthritis, Mycobacterium marinum, Immunosuppressive agents, Atypical mycobacteria

\section{Background}

Rheumatoid arthritis (RA) is the most common type of inflammatory arthritis worldwide with a prevalence of about $1 \%$ [1]. Over the past 20 years, the development and use of different immunosuppressive diseasemodifying antirheumatic drugs (DMARDs) has been steadily increasing [2]. With the advent of biosimilars (bsDMARDs) and the subsequent cost reduction, their use is likely to increase further. While this has clearly

\footnotetext{
* Correspondence: peter.korsten@med.uni-goettingen.de

'Department of Nephrology and Rheumatology, University Medical Center

Göttingen, Robert-Koch-Str. 40, D-37075 Göttingen, Germany

Full list of author information is available at the end of the article
}

been beneficial for many patients, side effects, such as infections, occur more frequently [3]. The use of immunosuppressants, particularly tumor necrosis factor-alpha inhibitors (TNF-i), can render patients susceptible to infections with Mycobacterium tuberculosis (MT) or to a reactivation of a latent tuberculosis [4]. In addition to $\mathrm{MT}$, there is a large number of nontuberculous mycobacteria (NTM), which represent the majority of mycobacteria [5]. They can infect humans as well as animals, as they inhabit a variety of similar surroundings, such as drinking water or natural waters [6, 7]. A particular risk factor for acquiring an infection with NTM is the frequent use of immunosuppressants [8].

C The Author(s). 2020 Open Access This article is distributed under the terms of the Creative Commons Attribution 4.0 International License (http://creativecommons.org/licenses/by/4.0/), which permits unrestricted use, distribution, and 


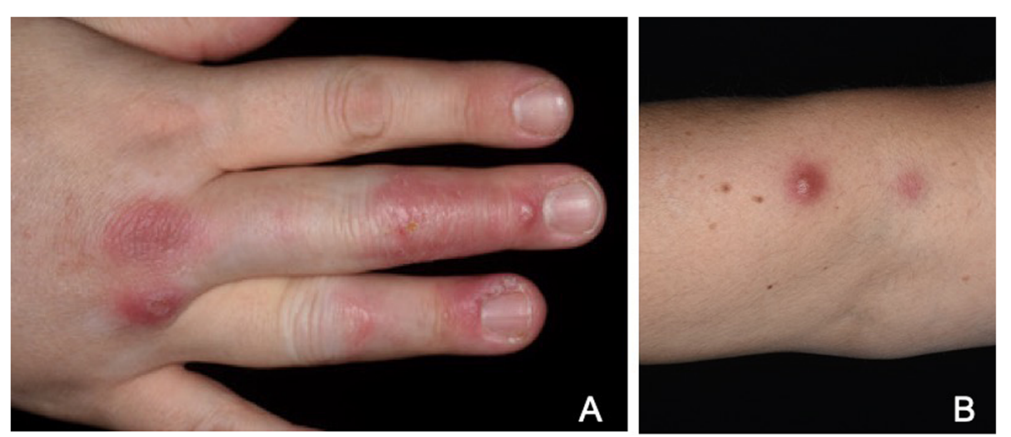

Fig. 1 Clinical images of the patient (a) Reddish-purplish discoloration on the back of the distal and intermediate phalanges of the third and fourth finger as well as the third and fourth metacarpophalangeal joint. On the base of the erythema, there are several formed papules and nodules with a central golden scab. b Reddish-purplish nodule on the proximal forearm

Among the NTM, one species is Mycobacterium marinum (MM). This bacterium, occurring in both salt and fresh water, grows optimally at a temperature between 30 and $32{ }^{\circ} \mathrm{C}$ [9] and, in case of an infection, shows an incubation time of typically two to 4 weeks [10]. It can lead to diseases in various fish species and subsequently to infections in humans who come into contact with infected fish or contaminated water, for example during the cleaning process of aquaria by direct inoculation into previously injured tissue [10,11]. Usually, superficial soft tissue infections occur with the formation of red nodules, ulcerations and abscesses [12-14]. In some cases, however, tenosynovitis, arthritis and osteomyelitis may occur $[15,16]$.

Here, we present the case of a female patient with known RA treated with immunosuppressive therapy who presented with pain of her right hand secondary to an infection with $M M$. In addition, we reviewed the literature for similar cases in order to provide clinicians with an overview on the topic.

\section{Case presentation}

The 45-year-old female patient had received a diagnosis of seronegative RA 4 years before presentation. She had received several DMARDs including methotrexate (MTX), sulfasalazine (SSZ), and hydroxychloroquine (HCQ). Her current treatment included leflunomide (LEF) and intermittent usage of low-dose prednisolone. Her past medical history was significant for arterial hypertension, which was treated with metoprolol and amlodipine.

The patient presented with acute symptoms, as she had been suffering from increasing pain and swelling of her right hand. Two weeks before presentation, she had already taken $20 \mathrm{mg}$ prednisolone for 10 days with only slight improvement of symptoms. On presentation, there was swelling and tenderness of the third metacarpophalangeal (MCP) joint of the right hand. A flare of her RA was assumed and prednisone increased to $40 \mathrm{mg}$ daily. Another 2 weeks later, she returned for a follow-up visit with new cutaneous findings: Clinical examination at that time revealed a visible and palpable swelling of the back of the right hand and third MCP joint (Fig. 1a). Other joints were not affected. A musculoskeletal ultrasound was performed and showed tenosynovitis of the third extensor tendon with increased power doppler signal (Fig. 2a and b). Laboratory analysis showed a thrombocytosis of $422 \times 10^{\wedge} 3 / \mu \mathrm{l}$ (normal range, NR: 150-

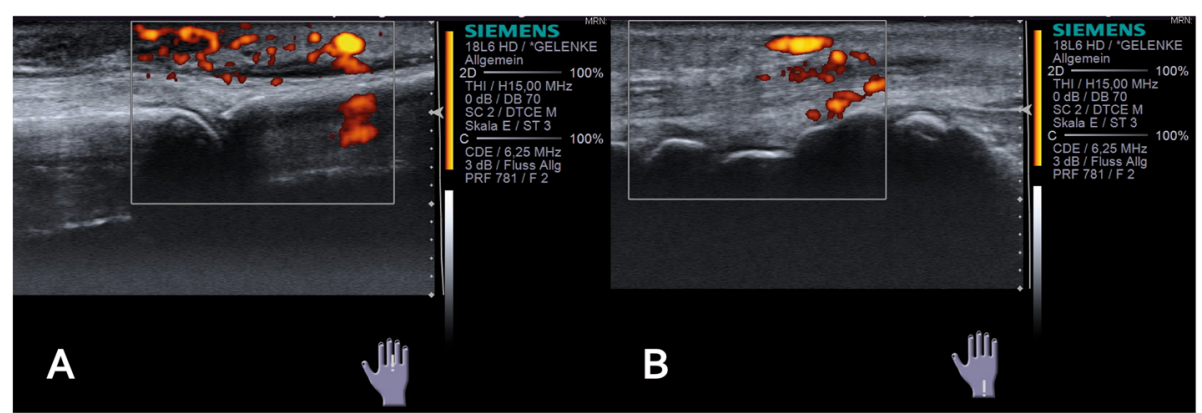

Fig. 2 Ultrasound images of the third metacarpophalangeal joint. a Longitudinal view of the third metacarpophalangeal joint showing intense power doppler signaling $\mathrm{II}^{\circ}$. $\mathbf{b}$ Longitudinal view of the carpal bones demonstrating tenosynovitis of the fourth extensor tendon sheath with power doppler signaling $1 \mathrm{I}^{\circ}$ 


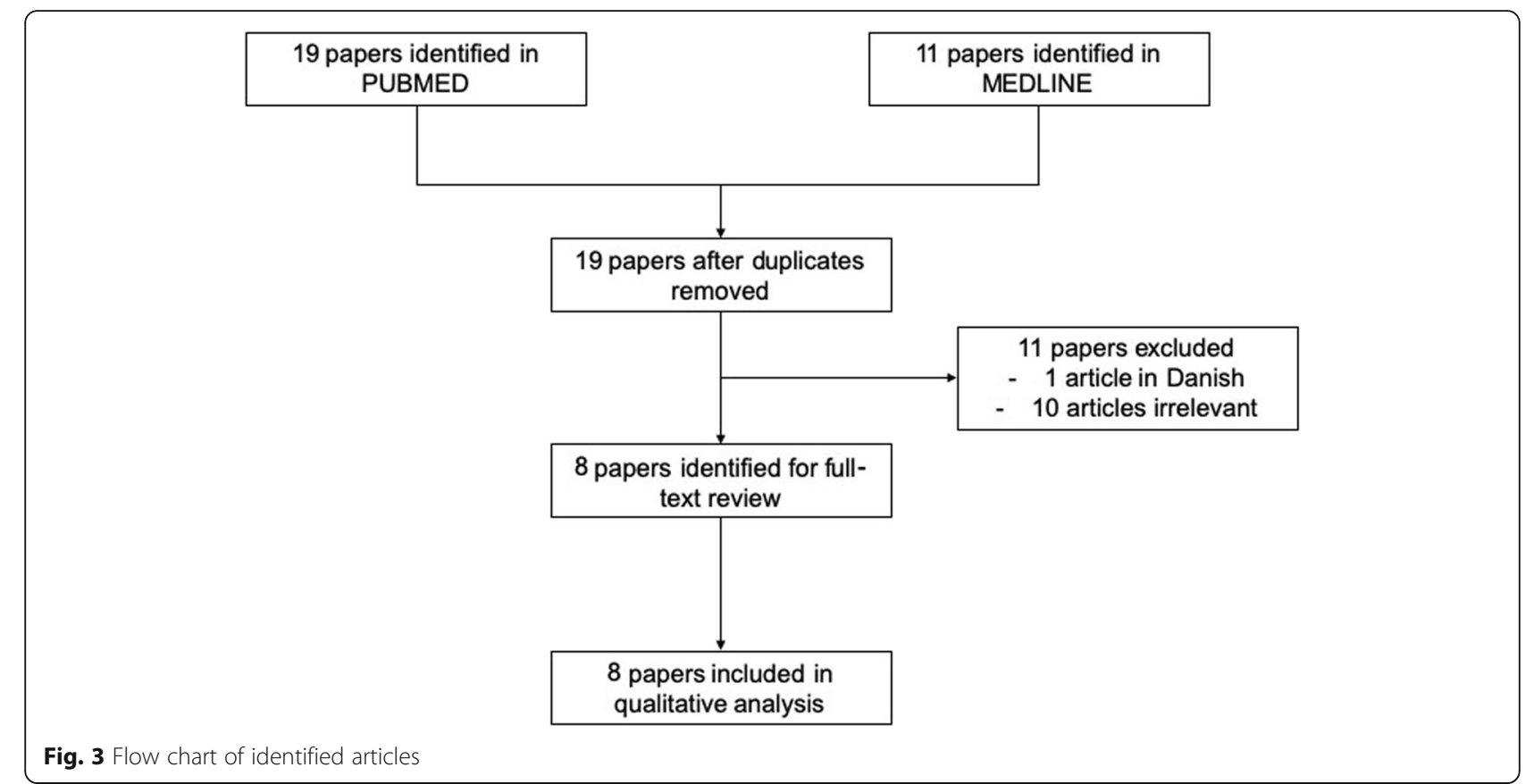

$\left.350 \times 10^{\wedge} 3 / \mu \mathrm{l}\right)$, a leukocytosis of $15,9 \times 10^{\wedge} 3 / \mu \mathrm{l}$ (NR: $4-$ $\left.11 \times 10^{\wedge} 3 / \mu \mathrm{l}\right)$ and slightly increased CRP of $7,6 \mathrm{mg} / \mathrm{l}$ (NR: $\leq 5 \mathrm{mg} / \mathrm{l})$. The differential blood count showed increased neutrophilic granulocytes with 83,9\% (NR: 40$76 \%)$. Otherwise, there were no pathological findings.

Due to the novel skin findings, the patient was urgently referred to our institution's Dermatology Clinic. In addition to the findings on the right hand, a complete examination of the skin revealed a single reddish- purplish erythematous nodule in a linear "sporotrichoid" form on the right proximal forearm (Fig. 1b). No palpable lymph nodes were found in the axillary region. Upon further questioning, the patient reported regular cleaning of fish tanks and recent travel to the seaside. A clinical diagnosis of a so-called "swimmer's granuloma" was made and a biopsy scheduled for microbiological analysis. In light of this information, the nailfolds of the third and fourth right finger seemed to be the most

Table 1 Detailed review of published cases

\begin{tabular}{|c|c|c|c|c|c|}
\hline $\begin{array}{l}\text { First author, } \\
\text { year }\end{array}$ & $\begin{array}{l}\text { Timing of onset } \\
\text { of infection }\end{array}$ & Clinical symptoms & $\begin{array}{l}\text { Immunosuppressive } \\
\text { agents used }\end{array}$ & Treatment & Outcome \\
\hline Böcher, 2002 & Not described & $\begin{array}{l}\text { livid nodules on hands, forearms, and feet, } \\
\text { necrotizing skin ulcers, tendon rupture; fever }\end{array}$ & MTX & $\begin{array}{l}\text { CPF, ETA, } \\
\text { CLM }\end{array}$ & Clinical remission \\
\hline Chopra, 2003 & $\begin{array}{l}2 \text { years after RA- } \\
\text { diagnosis }\end{array}$ & wrist swelling of the right hand & ETN & CLM & Clinical remission \\
\hline Roddy, 2008 & $\begin{array}{l}5 \text { years after RA- } \\
\text { diagnosis }\end{array}$ & $\begin{array}{l}\text { erythematous macules and papules. Following } \\
\text { progression to pustules and fluctuant nodules, } \\
\text { which both hands and arms }\end{array}$ & MTX & $\begin{array}{l}\text { CPF, CLM, } \\
\text { DXC }\end{array}$ & still recovering \\
\hline Hess, 2009 & Not described & $\begin{array}{l}\text { right fourth digit was swollen and associated with } \\
\text { fissuring and crusting; subcutaneous nodules on } \\
\text { dorsal hand and forearm }\end{array}$ & MTX, SSZ, INF & $\begin{array}{l}\text { AZM, ETA, } \\
\text { TMT }\end{array}$ & $\begin{array}{l}\text { improvement but still } \\
\text { significant functional } \\
\text { impairment of the finger }\end{array}$ \\
\hline Danko, 2009 & $\begin{array}{l}15 \text { years after } \\
\text { RA-diagnosis }\end{array}$ & $\begin{array}{l}\text { erythematous nodules on upper thighs and lower } \\
\text { lip }\end{array}$ & MTX, INF & $\begin{array}{l}\text { RAP, INH, } \\
\text { PZA, ETA }\end{array}$ & No new lesions \\
\hline Caron, 2011 & $\begin{array}{l}\text { Treatment over } \\
\text { the previous } 18 \\
\text { months }\end{array}$ & $\begin{array}{l}\text { Inflammatory lesion on her right index and } \\
\text { nodules on the ipsilateral forearm }\end{array}$ & ADA & CLM, MC & Clinical remission \\
\hline Bakker, 2913 & Not described & $\begin{array}{l}\text { Erythematous livid papules and necrotic nodules } \\
\text { on right hand and both legs }\end{array}$ & MTX, ADA & ETA, CLM & Clinical remission \\
\hline $\begin{array}{l}\text { Papathemell, } \\
2016\end{array}$ & Not described & subcutaneous nodules on her legs & $L E F, A Z A$ & $\begin{array}{l}\text { ETA, CLM, } \\
\text { RAP }\end{array}$ & Stabilization of the disease \\
\hline
\end{tabular}

ADA adalimumab, AZA azathioprine, AZM azithromycine, CPF ciprofloxacine, CLM clarithromycine, DXC doxycycline, ETA ethambutol, ETN etanercept, INF infliximab, INH isoniazid, LEF leflunomide, MTX methotrexate, MC minocycline, PZA pyrazinamide, RFB rifabutin, RAP rifampicine, SSZ sulfasalazine, TMT trimethaprim 


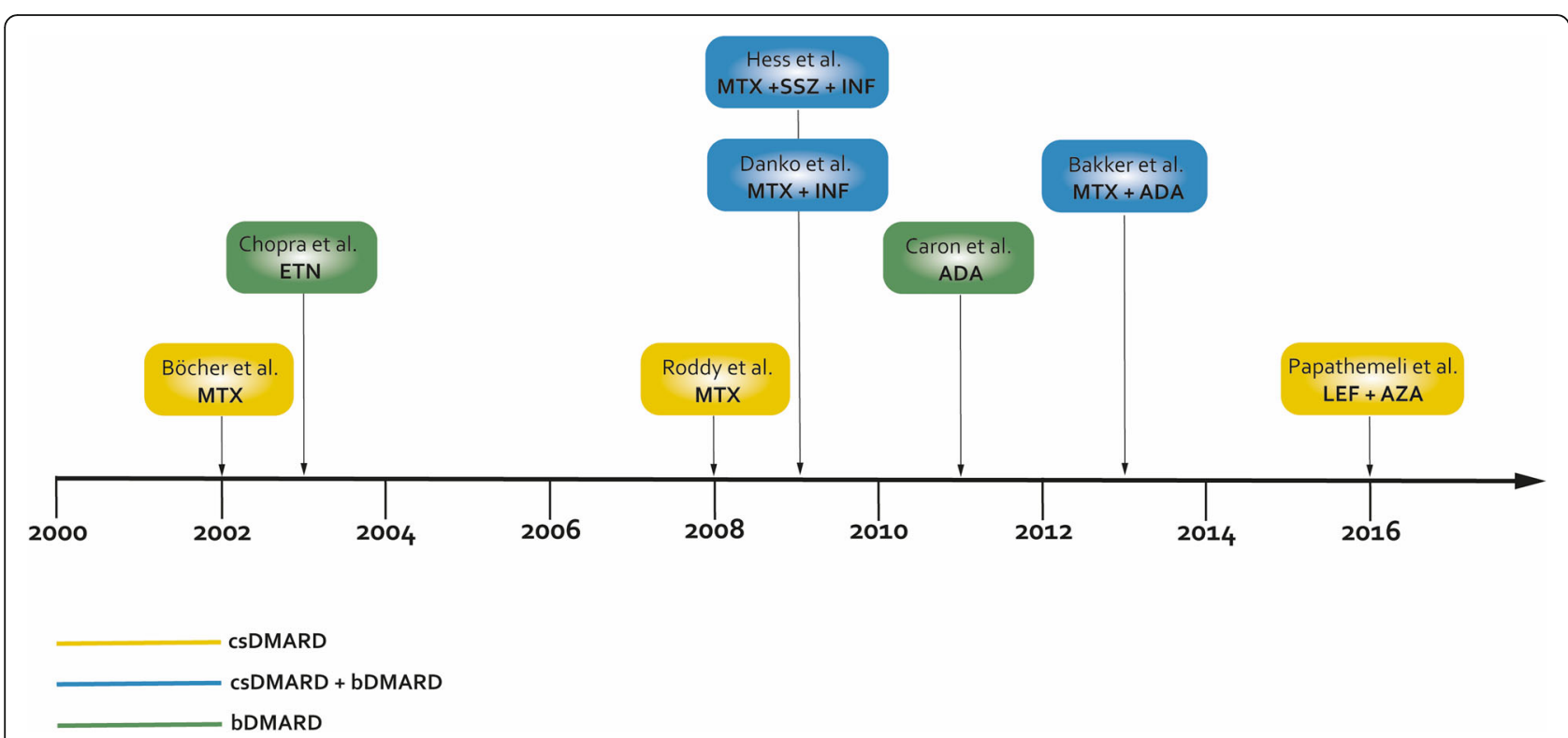

Fig. 4 Overview of published cases in relation to treatment with conventional or biological disease-modifying anti-rheumatic drugs. ADA, adalimumab; AZA, azathioprine; b, biological; cs, conventional synthetic; DMARD, disease-modifying anti-rheumatic drug; ETN, etanercept; INF, infliximab; LEF, leflunomide, MTX, methotrexate, SSZ, sulfasalazine

likely site of inoculation. The histopathological analysis revealed granulomatous inflammation with necrosis. Ziehl-Neelsen staining and blood-based testing for Mycobacterium tuberculosis (using Quantiferon TB Gold Plus $^{\bullet}$ test) were negative. After several weeks, infection with $M M$ was confirmed in the tissue culture.

\section{Treatment and outcome}

Based on the clinical findings, immediate antibiotic treatment with clarithromycin and rifampicin was initiated. There was gradual improvement of the clinical findings over the following months.

\section{Discussion and conclusions}

In the present case, the patient presented with swelling of one joint and sonographic examination confirmed intense inflammation. Thus, both a flare of her RA and infectious complications needed to be considered. This differentiation is notoriously difficult [17-19]. Of note, the skin findings had not been present during the first clinic visit. Therefore, an important step in the management of this patient was a close follow-up and appropriate referral to Dermatology after the appearance of new skin findings, where the correct diagnosis was made.

The appearance of satellite lesions proximal to the entry site, as in our case, is likely due to lymphatic spread and critical for the diagnosis: This type of spread has been coined as "sporotrichoid", as it resembles a fungal infection with Sporothrix schenkii. There are various clinical variants described with this latter agent, the one closest resembling an infection with $M M$ is the "lymphocutaneous" phenotype [20, 21]. Very few agents appear in a similar pattern: These include $M M$, Sporothrix schenkii, nocardiosis, leishmaniasis, tularemia, and other bacterial or fungal infections [21].

The diagnosis of a $M M$ infection can be achieved with typical clinical findings of a "swimmer's granuloma" and confirmation of the pathogen in tissue culture. It should

Table 2 Characteristics differentiating Mycobacterium marinum infection from rheumatoid arthritis flare

\begin{tabular}{lll}
\hline & Favoring MM infection & Favoring RA flare \\
\hline Arthritis & Rare & Frequent \\
Tenosynovitis & Rare & Frequent \\
Skin findings & $\begin{array}{l}\text { Typical swimmer's granuloma with reddish-purplish } \\
\text { discolouration }\end{array}$ & $\begin{array}{l}\text { Rare presence of rheumatoid vasculitis or pyoderma } \\
\text { gangraenosum }\end{array}$ \\
Laboratory findings & $\begin{array}{l}\text { Elevated inflammatory markers (White blood count, C- } \\
\text { reactive protein) }\end{array}$ & Leukocytosis rare \\
Response to glucocorticoid & No improvement & Usually improves
\end{tabular}


be noted that the biopsy must be cultured at a temperature between 30 and $32^{\circ} \mathrm{C}$ for a period of 6 weeks. A positive culture can be obtained in about 70$80 \%$ of cases [10]. The therapy consists of a combined antibiotic therapy of either ethambutol or clarithromycin with rifampicin, and potentially also surgical debridement [22].

We searched PubMed and MEDLINE (using the search terms "Mycobacterium marinum" AND "rheumatoid arthritis") for cases where $M M$ infection occurred secondary to immunosuppressive therapy or mimicked RA at first presentation. 19 publications were identified. After review of these, eleven were excluded (Fig. 3). We further analyzed the remaining eight cases and compared them qualitatively with our case (Table 1).

In the case presented within this report, the patient received a single cDMARD therapy with LEF. In two of the eight cases, there was also a single conventional DMARD. Both of these patients received MTX [23, 24]. In two other cases, there was a single therapy with a bDMARD. The patients received Etanercept and Adalimumab $[25,26]$. In the majority of published cases, a combination therapy with a CDMARD and a bDMARD was present [27-29]. In one published case a combination of two cDMARDs and one bDMARD was described [30]. In five of the included cases the patients received either single therapy with a TNF-i or a combination therapy of a TNF-i with another drug $[25-28,30]$. Figure 4 summarizes the published cases.

In more than half of the published cases, a TNF-i was included in the therapeutic regimen. It is known from several studies that TNF-i increase the risk of reactivation of a latent tuberculosis and new infection with tuberculosis [4]. Therefore, testing for concomitant or dormant MT infection before initiation of therapy with these agents is considered standard of care. Nevertheless, despite this testing, infections with NTM may occur.

However, other predisposing factors also seem to exist: It may be sufficient to receive a single immunosuppressive agent in the presence of a superficial injury to promote infections with $M M$. Based on our literature review, no single agent with an exceptionally high risk could be identified. Of note, however, agents with a different mechanism of action, such as co-stimulation blockers (abatacept), anti-interleukin 6-blockers (tocilizumab, sarilumab), b-cell depleting agents (rituximab) or janus kinase inhibitors (baricitinib, tofacitinib) have not been associated with $M M$ infections.

In summary, the occurrence of $M M$ infection in the presence of DMARD therapy is very rare. One explanation is that it is generally a very rare infection, even in the immunocompetent population. Another possible explanation is that these infections are often misjudged clinically as a flare of existing RA. Table 2 summarizes potential characteristics which may differentiate an $M M$ infection from a RA flare.

The reported case highlights the importance of clinical judgement in the assessment and follow-up of RA patients treated with DMARDs, since complications may arise and can be mistaken for a flare of the underlying disease. Therefore, further diagnostic interventions including biopsy and microbiological studies may be required, especially in patients not responding as expected to immunosuppressive agents. The most important clinical clue in this case was the appearance of new skin lesions which, ultimately, led to the correct diagnosis.

\section{Abbreviations \\ CRP: C-reactive protein; DMARD: Disease-modifying anti-rheumatic drugs; HCQ: Hydroxychloroquine; LEF: Leflunomide; MCP: Metacarpophalangeal; MM: Mycobacterium marinum; MT: Mycobacterium tuberculosis; MTX: Methotrexate; NTM: Non-tuberculous mycobacteria; RA: Rheumatoid arthritis; SSZ: Sulfasalazine; TNF-i: TNF-alpha inhibitor}

\section{Acknowledgements}

The authors are indebted to the patient who provided written informed consent for publication of this manuscript.

\section{Authors' contributions}

NS wrote the first draft, reviewed the literature, edited the manuscript and drafted figures. TS treated the patient, provided figures, reviewed and edited the manuscript. MP reviewed and edited the final version of the manuscript. PK conceived the study, treated the patient, reviewed the literature, contributed figures, and edited the manuscript. All authors read and approved the final version of the manuscript.

Funding

The authors received no specific funding related to this article.

Availability of data and materials

All data are contained within the manuscript.

\section{Ethics approval}

For case reports, our institution does not require formal approve by an ethics committee. The publication is in agreement with the Declaration of Helsinki and the patient provided written consent for publication.

\section{Consent for publication}

The patient provided written informed consent for publication of this article. A copy of the statement is available to the journal.

\section{Competing interests}

The authors declare that they have no competing interests.

\section{Author details}

${ }^{1}$ Department of Nephrology and Rheumatology, University Medical Center Göttingen, Robert-Koch-Str. 40, D-37075 Göttingen, Germany. ²Department of Dermatology, Venereology, and Allergology, University Medical Center Göttingen, Göttingen, Germany.

Received: 23 September 2019 Accepted: 10 January 2020

Published online: 16 March 2020

References

1. Smolen JS, Aletaha D, Barton A, et al. Rheumatoid arthritis. Nat Rev Dis Primer. 2018;4:18001. https://doi.org/10.1038/nrdp.2018.1.

2. Burmester GR, Bijlsma JWJ, Cutolo M, Mclnnes IB. Managing rheumatic and musculoskeletal diseases - past, present and future. Nat Rev Rheumatol. 2017;13:443-8. https://doi.org/10.1038/nrrheum.2017.95.

3. Singh JA, Cameron C, Noorbaloochi $S$, et al. Risk of serious infection in biological treatment of patients with rheumatoid arthritis: a systematic 
review and meta-analysis. Lancet Lond Engl. 2015;386:258-65. https://doi. org/10.1016/S0140-6736(14)61704-9.

4. Diel R, Hauer B, Loddenkemper R, et al. Empfehlungen für das Tuberkulosescreening vor Gabe von TNF-a-Inhibitoren bei rheumatischen Erkrankungen. Pneumologie. 2009;63:329-34. https://doi.org/10.1055/s-00291214673.

5. Tortoli E. Impact of genotypic studies on mycobacterial taxonomy: the new mycobacteria of the 1990s. Clin Microbiol Rev. 2003;16:319-54. https://doi. org/10.1128/CMR.16.2.319-354.2003.

6. Falkinham JO. Nontuberculous mycobacteria in the environment. Clin Chest Med. 2002;23:529-51.

7. Falkinham JO. Environmental sources of nontuberculous mycobacteria. Clin Chest Med. 2015;36:35-41. https://doi.org/10.1016/j.ccm.2014.10.003.

8. Falkinham JO. Surrounded by mycobacteria: nontuberculous mycobacteria in the human environment. J Appl Microbiol. 2009;107:356-67. https://doi. org/10.1111/j.1365-2672.2009.04161.x

9. Griffith DE, Aksamit T, Brown-Elliott BA, et al. An official ATS/IDSA statement: diagnosis, treatment, and prevention of Nontuberculous mycobacterial diseases. Am J Respir Crit Care Med. 2007;175:367-416. https://doi.org/10. 1164/rccm.200604-571ST.

10. Gluckman SJ. Mycobacterium marinum. Clin Dermatol. 1995:13:273-6. https://doi.org/10.1016/0738-081X(95)00023-9.

11. Collins $\mathrm{CH}$, Grange JM, Noble WC, Yates MD. Mycobacterium marinum infections in man. Epidemiol Infect. 1985;94:135-49. https://doi.org/10.1017/ S0022172400061349.

12. Kullavanijaya P, Sirimachan S, Bhuddhavudhikrai P. Mycobacterium MARINUM cutaneous infections acquired from occupations and hobbies. Int J Dermatol. 1993;32:504-7. https://doi.org/10.1111/j.1365-4362.1993.tb02834. $\mathrm{x}$.

13. Aubry A, Chosidow O, Caumes E, et al. Sixty-three cases of Mycobacterium marinum infection: clinical features, treatment, and antibiotic susceptibility of causative isolates. Arch Intern Med. 2002;162:1746-52. https://doi.org/10. 1001/archinte.162.15.1746.

14. Liao CH, Lai CC, Ding LW, et al (2007) Skin and soft tissue infection caused by non-tuberculous mycobacteria. https://www.ingentaconnect.com/ content/iuatld/ijtld/2007/00000011/00000001/art00016. Accessed 13 Apr 2019

15. Clark RB, Spector H, Friedman DM, et al. Osteomyelitis and synovitis produced by Mycobacterium marinum in a fisherman. J Clin Microbiol. 1990;28:2570-2.

16. Vazquez JA, Sobel JD. A case of disseminatedMycobacterium marinum infection in an immunocompetent patient. Eur J Clin Microbiol Infect Dis. 1992;11:908-11. https://doi.org/10.1007/BF01962371.

17. Thanou-Stavraki A, Sawalha AH, Crowson AN, Harley JB. Noodling and Mycobacterium marinum infection mimicking seronegative rheumatoid arthritis complicated by anti-tumor necrosis factor a therapy. Arthritis Care Res. 2011;63:160-4. https://doi.org/10.1002/acr.20303.

18. Slany M, Jezek P. Bodnarova M (2013) fish tank granuloma caused by Mycobacterium marinum in two aquarists: two case reports. Biomed Res Int. 2013. https://doi.org/10.1155/2013/161329.

19. Lata CJ, Edgar K, Vaughan S. Clinical Implications for the timely diagnosis of Mycobacterium marinum in the age of biologic therapy: a case report and review of the literature. Case Rep Infect Dis. 2017, 2017. https://doi.org/10. $1155 / 2017 / 5274302$

20. Kauffman CA. Sporotrichosis. Clin Infect Dis Off Publ Infect Dis Soc Am. 1999;29:231-6; quiz 237. https://doi.org/10.1086/520190.

21. Schwendiman MN, Johnson RP, Henning JS. Subcutaneous nodules with sporotrichoid spread. Dermatol Online J. 2009;15(5):11.

22. Rallis E, Koumantaki-Mathioudaki E. Treatment of Mycobacterium marinum cutaneous infections. Expert Opin Pharmacother. 2007;8:2965-78. https:// doi.org/10.1517/14656566.8.17.2965.

23. Böcher W, Galle PR, Märker-Hermann E. Hautknoten und Ulzera der Extremitäten bei einem Patienten mit rheumatoider Arthritis. DMW - Dtsch Med Wochenschr. 2002;127:735-8. https://doi.org/10.1055/s-2002-24401.

24. Roddy K, Kao G, Dawn M, et al. The arthritic fisherman. Am J Med. 2008;121: 287-9. https://doi.org/10.1016/j.amjmed.2008.01.019.

25. Chopra N, Kirschenbaum A, Widman D. Mycobacterium marinum tenosynovitis in a patient on Etanercept therapy for rheumatoid arthritis. Jcr J Clin Rheumatol. 2002;8:265-8.

26. Caron J, Michot C, Fabre S, et al. Aggressive cutaneous infection with Mycobacterium marinum in two patients receiving anti-tumor necrosis factor-alfa agents. J Am Acad Dermatol. 2011;65:1060-2. https://doi.org/10. 1016/j.jaad.2008.12.041.

27. Danko JR, Gilliland WR, Miller RS, Decker CF. Disseminated Mycobacterium marinum infection in a patient with rheumatoid arthritis receiving infliximab therapy. Scand J Infect Dis. 2009;41:252-5. https://doi.org/10.1080/ 00365540902774599

28. Bakker CV, Kardaun SH, Wilting KR, et al. Why you should ask your patients about their fishing hobbies. Neth J Med. 2013;71:3.

29. Papathemeli D, Franke I, Bonnekoh B, et al. Explosive generalization of nodular vasculitis - Mycobacterium marinum challenges the paradigm. J Eur Acad Dermatol Venereol. 2016;30:e189-91. https://doi.org/10.1111/jdv. 13498.

30. Hess SD, Van Voorhees AS, Chang LM, et al. Subcutaneous Mycobacterium marinum infection in a patient with chronic rheumatoid arthritis receiving immunosuppressive therapy. Int J Dermatol. 2009:48:782-3. https://doi.org/ 10.1111/j.1365-4632.2009.03934.x.

\section{Publisher's Note}

Springer Nature remains neutral with regard to jurisdictional claims in published maps and institutional affiliations.

\section{Ready to submit your research? Choose BMC and benefit from:}

- fast, convenient online submission

- thorough peer review by experienced researchers in your field

- rapid publication on acceptance

- support for research data, including large and complex data types

- gold Open Access which fosters wider collaboration and increased citations

- maximum visibility for your research: over $100 \mathrm{M}$ website views per year

At BMC, research is always in progress.

Learn more biomedcentral.com/submissions 